\title{
A standard photomap of ovarian nurse cell chromosomes and inversion polymorphism in Anopheles beklemishevi
}

\author{
Gleb N. Artemov', Mikhail I. Gordeev², Alina A. Kokhanenko', Anton V. Moskaev², Alena I. Velichevskaya',
} Vladimir N. Stegniy ${ }^{1}$, Igor V. Sharakhov ${ }^{1,3^{*}}$ and Maria V. Sharakhova ${ }^{1,3^{*}}$

\begin{abstract}
Background: Anopheles beklemishevi is a member of the Maculipennis group of malaria mosquitoes that has the most northern distribution among other members of the group. Although a cytogenetic map for the larval salivary gland chromosomes of this species has been developed, a high-quality standard cytogenetic photomap that enables genomics and population genetics studies of this mosquito at the adult stage is still lacking.

Methods: In this study, a cytogenetic map for the polytene chromosomes of An. beklemishevi from ovarian nurse cells was developed using high-resolution digital imaging from field collected mosquitoes. PCR-amplified DNA probes for fluorescence in situ hybridization (FISH) were designed based on the genome of An. atroparvus. The DNA probe obtained by microdissection procedures from the breakpoint region was labelled in a DOP-PCR reaction. Population analysis was performed on 371 specimens collected in 18 locations.

Results: We report the development of a high-quality standard photomap for the polytene chromosomes from ovarian nurse cells of An. beklemishevi. To confirm the suitability of the map for physical mapping, several PCRamplified probes were mapped to the chromosomes of An. beklemishevi using FISH. In addition, we identified and mapped DNA probes to flanking regions of the breakpoints of two inversions on chromosome $X$ of this species. Inversion polymorphism was determined in 13 geographically distant populations of An. beklemishevi. Four polymorphic inversions were detected. The positions of common chromosomal inversions were indicated on the map.

Conclusions: The study constructed a standard photomap for ovarian nurse cell chromosomes of An. beklemishevi and tested its suitability for physical genome mapping and population studies. Cytogenetic analysis determined inversion polymorphism in natural populations of An. beklemishevi related to this species' adaptation.
\end{abstract}

Keywords: Anopheles, Mosquito, Cytogenetic map, Inversion polymorphism, Physical mapping

\section{Background}

The malaria mosquito Anopheles beklemishevi Stegniy \& Kabanova, 1976 [1] is a member of the Maculipennis group [2]. This group of mosquitoes has a wide distribution range in Eurasia and North America. Among members of the group, An. beklemisevi has the most northern distribution in Eurasia [3]. It occupies the territory from the East coast of the Baltic Sea to the basin of the Lena River and from

\footnotetext{
*Correspondence: igor@vt.edu; msharakh@vt.edu

${ }^{1}$ Laboratory of Ecology, Genetics and Environmental Protection, Tomsk State University, Tomsk, Russia

Full list of author information is available at the end of the article
}

the forest-tundra zone to the Altai and Sayan Mountain systems. The northern border of this species distribution in Russia lies to the North of the Arctic Circle. The geographical range of $A n$. beklemishevi in the North substantially overlaps with the distribution of another Palearctic member of the Maculipennis group, An. messeae [4], which has wider distribution in western and southern Eurasia. As the most widespread mosquito in Eurasia, An. messeae is considered a dominant malaria vector in Eurasia [5]. Although An. beklemishevi is recognized as a malaria vector in Russia and Europe [6], it does not play an important role in malaria transmission because of its exophylic behavior and 
ecological preferences to high altitudes and swampy territories [3]. In fact, the ability of An. beklemishevi to transmit malaria has never been studied experimentally [7].

To date, only one cytogenetic map based on polytene chromosomes from the salivary glands has been developed for An. beklemishevi [8]. Images of chromosomes stained with lacto-aceto-orsein were obtained using photo films. According to the map, the polytene chromosomal complement of An. beklemishevi consists of three chromosomes with five chromosomal arms, which is the same as in other Anopheles species [9]. The $\mathrm{X}$ chromosome contains one arm, and both autosomes contain two chromosomal arms. Chromosomes on the map were numbered in the order of increasing size as in the nomenclature developed before [10]. Thus, the biggest autosome is chromosome 3. Chromosomes were subdivided into 39 regions in accordance with other chromosomal maps developed for the species from the Maculipennis group [11]. Landmarks for the chromosomal arm recognition were described in detail [8].

The cytogenetic map in the original study [8] has been successfully used to investigate inversion polymorphism in An. beklemishevi. Twelve polymorphic inversions have been identified in 1000 mosquito specimens from 15 populations distributed over the entire geographic range of the species. Five inversions were found on the longest chromosome arm $3 R$. Three inversions were detected on the $2 \mathrm{R}$ arm. Two inversions were observed on sex chromosome $\mathrm{X}$, and only one inversion was detected in each of the $2 \mathrm{~L}$ and $3 \mathrm{~L}$ arms. Only two inversions, which are on the $\mathrm{X}$ chromosome, were highly polymorphic. Two individuals were homozygotes for one of the inversions on the $\mathrm{X}$ chromosome. In general, inversion polymorphism in $A n$. beklemishevi remains understudied in comparison with An. messeae [12-19]. Moreover, because of the absence of a standard photomap for ovarian nurse cell chromosomes, the adult stage was excluded from the inversion polymorphism analysis.

In this study, we developed a high-quality standard cytogenetic photomap for ovarian nurse cell chromosomes of An. beklemishevi. We mapped four DNA probes amplified by polymerase chain reaction (PCR-amplified) on X, 2R, 3R, and 3L chromosome arms of An. beklemishevi. We also mapped the $\mathrm{X}$ chromosome inversion breakpoints using microdissected DNA probes. The original salivary gland map [8] and newly developed ovarian nurse cell map were used for the analysis of the inversion polymorphism at larval and adult stages, respectively. Thirteen distantly located populations of $A n$. beklemishevi were analyzed and compared. Our study has demonstrated that a standard photomap of ovarian nurse cell chromosomes can be successfully utilized for physical genome mapping and for population genetic studies of the inversion polymorphism in $A n$. beklemishevi.

\section{Methods}

Mosquito collection and ovary preservation

For the cytogenetic map development, An. beklemishevi mosquitoes were collected from a natural population in Chainsk (Tomsk region, Russia) in July and August of 2015 and in June of 2016 (Table 1). Ovaries of half-gravid females were dissected and fixed in Carnoy's solution (3:1 ethanol: glacial acetic acid by volume). Ovaries were preserved in Carnoy's solution from $24 \mathrm{~h}$ up to 1 month at $-20{ }^{\circ} \mathrm{C}$. For the inversion polymorphism analysis, mosquitoes were collected from 13 distant localities in Eurasia (Table 1). We studied a total of 371 mosquitoes from 18 collections comprised of 110 adults and 261 larvae. Collections in two populations, Kolarovo and Teguldet in Western Siberia, were conducted repeatedly during 3 and 4 years, respectively. The latter specimens were fixed in Carnoy's solution and stored at $5{ }^{\circ} \mathrm{C}$.

\section{Chromosome preparation and species identification}

For one preparation of ovarian nurse cell chromosomes, approximately a third part of a single ovary from one pair was taken. It is important to avoid having an excess of tissue on the slide for obtaining high-quality chromosome spreads. Ovaries were held for $5 \mathrm{~min}$ in a drop of $50 \%$ propionic acid, macerated and squashed. The quality of preparations was examined under an AxioImager A1 microscope (Carl Zeiss, OPTEC LLC, Novosibirsk, Russia). High-quality preparations were frozen in liquid nitrogen, and coverslips were removed. Preparations were dehydrated in an ethanol series $(50 \%, 70 \%, 90 \%$, and $100 \%)$ and air dried. Identification of species was conducted based on chromosome banding pattern $[8,20]$ and heterochromatin morphology [21]. Chromosomal preparations from salivary glands of 4th instar larvae were performed as described earlier [22]. Salivary glands were stained in 2\% lacto-acetic-orcein for $45 \mathrm{~min}$ and squashed in $45 \%$ acetic acid. Karyotyping of polytene chromosomes was conducted using a Nikon, Eclipse E200 microscope (Nikon, BioVitrum, Moscow, Russia).

\section{Chromosome map development}

Chromosome images were observed using an AxioImager A1 microscope (Carl Zeiss) with an attached CCD camera MRc5 in phase contrast using an AxioVision version 4.7.1 software (Carl Zeiss). For the chromosome map development, about 250 images of well-polytenized and well-spread chromosomes were obtained. Images were combined, straightened, shaped, and cropped using Adobe-Photoshop CS2 software. Chromosome nomenclature was generally adopted from the previously published chromosome map for salivary glands of $A n$. beklemishevi $[8,20]$. 
Table 1 Chromosomal polymorphism in populations of An. beklemishevi. Frequencies of inversion X1 and X2 were determined for females

\begin{tabular}{|c|c|c|c|c|c|c|c|}
\hline \multirow[t]{2}{*}{ Locality(coordinates) } & \multirow{2}{*}{$\begin{array}{l}\text { Collection } \\
\text { date }\end{array}$} & \multicolumn{2}{|c|}{ Number } & \multicolumn{4}{|c|}{ Frequency of inversions } \\
\hline & & Total & Females & $\overline{x 1}$ & $\times 2$ & $3 R 1$ & $3 \mathrm{R} 3$ \\
\hline Kolarovo $\left(56^{\circ} 20^{\prime} \mathrm{N}, 84^{\circ} 56^{\prime} \mathrm{E}\right)$ & $07 / 04 / 1983$ & $23 \mathrm{~L}$ & $8 \mathrm{~L}$ & 0 & 0.0625 & 0 & 0 \\
\hline Kolarovo $\left(56^{\circ} 20^{\prime} \mathrm{N}, 84^{\circ} 56^{\prime} \mathrm{E}\right)$ & $07 / 05 / 2004$ & $6 \mathrm{~A}$ & $6 \mathrm{~A}$ & 0 & 0 & 0 & 0 \\
\hline Kolarovo $\left(56^{\circ} 20^{\prime} \mathrm{N}, 84^{\circ} 56^{\prime} \mathrm{E}\right)$ & $07 / 28 / 2005$ & $2 \mathrm{~A}$ & $2 \mathrm{~A}$ & 0 & 0 & 0 & 0 \\
\hline Teguldet $\left(57^{\circ} 18^{\prime} \mathrm{N}, 88^{\circ} 10^{\prime} \mathrm{E}\right)$ & 08/05/2003 & $6 \mathrm{~A}$ & $6 \mathrm{~A}$ & 0 & 0 & 0 & 0 \\
\hline Teguldet $\left(57^{\circ} 18^{\prime} \mathrm{N}, 88^{\circ} 10^{\prime} \mathrm{E}\right)$ & $07 / 12 / 2005$ & $27 \mathrm{~A}$ & $27 \mathrm{~A}$ & 0 & 0.1111 & 0 & 0 \\
\hline Teguldet $\left(57^{\circ} 18^{\prime} \mathrm{N}, 88^{\circ} 10^{\prime} \mathrm{E}\right)$ & 07/13/2006 & $4 \mathrm{~A}$ & $4 \mathrm{~A}$ & 0 & 0 & 0 & 0 \\
\hline Teguldet $\left(57^{\circ} 18^{\prime} \mathrm{N}, 88^{\circ} 10^{\prime} \mathrm{E}\right)$ & 08/01/2007 & $8 \mathrm{~A}$ & $8 \mathrm{~A}$ & 0 & 0 & 0 & 0 \\
\hline Artybash $\left(51^{\circ} 47^{\prime} \mathrm{N}, 87^{\circ} 15^{\prime} \mathrm{E}\right)$ & 07/26/2007 & $25 \mathrm{~L}$ & $13 \mathrm{~L}$ & 0 & 0.2308 & 0 & 0 \\
\hline Teletskoe Lake, Samysh River $\left(51^{\circ} 45^{\prime} \mathrm{N}, 87^{\circ} 22^{\prime} \mathrm{E}\right)$ & $07 / 27 / 2007$ & $14 \mathrm{~L}$ & $9 \mathrm{~L}$ & 0 & 0.1667 & 0 & 0 \\
\hline Teletskoe Lake, Koldor River $\left(51^{\circ} 47^{\prime} \mathrm{N}, 87^{\circ} 43^{\prime} \mathrm{E}\right)$ & $07 / 28 / 2007$ & $12 \mathrm{~L}$ & $5 \mathrm{~L}$ & 0 & 0 & 0 & 0 \\
\hline Teletskoe Lake, Kamga River $\left(51^{\circ} 20^{\prime} \mathrm{N}, 87^{\circ} 47^{\prime} \mathrm{E}\right)$ & $07 / 29 / 2007$ & $15 \mathrm{~L}$ & $7 \mathrm{~L}$ & 0 & 0 & 0 & 0 \\
\hline Dvorets $\left(57^{\circ} 56^{\prime} \mathrm{N}, 32^{\circ} 60^{\prime} \mathrm{E}\right)$ & 06/01/2009 & $36 \mathrm{~L}$ & $17 \mathrm{~L}$ & 0 & 0.3236 & 0 & 0 \\
\hline Segezha $\left(63^{\circ} 45^{\prime} \mathrm{N}, 34^{\circ} 46^{\prime} \mathrm{E}\right)$ & 08/16/2010 & $64 \mathrm{~L}$ & $36 \mathrm{~L}$ & 0 & 0.1389 & 0 & 0 \\
\hline Belomorsk (64. $\left.31^{\prime} \mathrm{N}, 34^{\circ} 46^{\prime} \mathrm{E}\right)$ & $08 / 14 / 2010$ & $36 \mathrm{~L}$ & $20 \mathrm{~L}$ & 0.0750 & 0.0500 & 0.0417 & 0.0139 \\
\hline Dmitrovskiy Pogost $\left(55^{\circ} 18^{\prime} \mathrm{N}, 39^{\circ} 50^{\prime} \mathrm{E}\right)$ & $07 / 23 / 2015$ & $27 \mathrm{~L}$ & $13 \mathrm{~L}$ & 0 & 0.1154 & 0 & 0 \\
\hline Parykino $\left(39^{\circ} 23^{\prime} \mathrm{N}, 55^{\circ} 17^{\prime} \mathrm{E}\right)$ & $07 / 24 / 2015$ & $4 \mathrm{~L}$ & $3 \mathrm{~L}$ & 0 & 0.3333 & 0 & 0 \\
\hline Gzhel $\left(55^{\circ} 36^{\prime} \mathrm{N}, 38^{\circ} 26^{\prime} \mathrm{E}\right)$ & 08/20/2015 & $5 \mathrm{~L}$ & $4 \mathrm{~L}$ & 0 & 0.1250 & 0 & 0 \\
\hline Chainsk $\left(57^{\circ} 55^{\prime} \mathrm{N}, 82^{\circ} 36^{\prime} \mathrm{E}\right)$ & $06 / 22 / 2016$ & $57 \mathrm{~A}$ & $57 \mathrm{~A}$ & 0.0088 & 0.1404 & 0 & 0 \\
\hline
\end{tabular}

Abbreviations: $L$ larvae, $A$ adult females

\section{Microdissection and DOP-PCR}

Microdissection of region $2 \mathrm{BC}$ from the $\mathrm{X}$ chromosome of the ovarian nurse cells and subsequent DOP-PCR (Degenerate Oligonucleotide Primers PCR) were performed accordingly to the previously published protocol [23]. Microdissection by glass needles was performed from air-dried squashed preparations of ovarian nurse cell polytene chromosomes of An. beklemishevi. A micro-dissected DNA material was amplified with DOP primers to achieve the necessary amount of the regionspecific DNA-probe. The DNA-probe was labeled in an additional PCR reaction in the presence of a fluorescently labelled nucleotide. The boundaries of the microdissected regions were chosen to represent the expected breakpoints of the polymorphic inversion.

\section{Gene-specific PCR}

Gene-specific primers were designed to amplify four unique exon sequences using PRIMER-BLAST software available at NCBI [24]. Genes from different chromosome arms of $A n$. beklemishevi were selected based on similarity with the An. atroparvus mapped genome [25]. The primer design was based on gene annotations from the AatrE1 genome assembly available at VectorBase [26]. PCR was performed in the presence of $1 \times$ PCR buffer (SibEnzyme Ltd., Novosibirsk, Russia), $2.5 \mathrm{mM} \mathrm{MgCl} 2$ (SibEnzyme Ltd., Novosibirsk, Russia), $0.2 \mathrm{mM}$ dNTP (Thermo Fisher Scientific, Waltham, MA, USA), and $0.02 \mathrm{u} / \mu \mathrm{l}$ Taq Polymerase (SibEnzyme Ltd.).

\section{DNA probe labelling and fluorescence in situ}

\section{hybridization}

The DNA probe obtained by microdissection procedures was labelled in a DOP-PCR reaction in the presence of TAMRA-5-dUTP as described earlier [23]. Fragments obtained by gene-specific PCR were labelled using a Random Primer Labelling protocol: $25 \mu \mathrm{l}$ of labelling reaction contained 50 ng DNA, 1× Klenow buffer (Thermo Fisher Scientific), $44 \mathrm{ng} / \mu \mathrm{l}$ Exo-Resistant Random Primer (Thermo Fisher Scientific) $0.1 \mathrm{mM}$ dATP, dGTP, dCTP, and $0.015 \mathrm{mM}$ dTTP, $0.016 \mathrm{mM}$ TAMRA5-dUTP, or Biotin-11-dUTP (Biosan, Novosibirsk, Russia), and $5 \mathrm{U}$ of Klenow fragment (Thermo Fisher Scientific TM) in a PCR tube. The required amounts of DNA, Klenow buffer, and Random Primers were mixed, brought up to $12 \mu \mathrm{l}$ with water, and heated at $95{ }^{\circ} \mathrm{C}$ for $5 \mathrm{~min}$ in a thermocycler. The solution was chilled on ice, and appropriate amounts of nucleotides, Klenow fragment, and water were added to reach $25 \mu$ l. The reaction mix was incubated at $37{ }^{\circ} \mathrm{C}$ for $18 \mathrm{~h}$. Fluorescence in situ hybridization (FISH) was performed using a previously described standard protocol $[25,27]$.

\section{Statistical analysis}

Frequencies of inversions were calculated as the fraction of all chromosomes in a population that carry the inversion. Chi-square test was used to examine whether inversion genotype frequencies were in Hardy-Weinberg equilibrium using an interactive calculation tool [28]. A 
$P$-value above 0.05 indicated that there are no significant differences between observed inversion frequencies in natural populations and expected inversion frequencies following the Hardy-Weinberg law (Additional file 1: Table S1).

\section{Results}

\section{A cytogenetic map for An. beklemishevi}

We developed a high-resolution map for polytene chromosomes from ovarian nurse cells of An. beklemishevi. As shown before [8], the chromosome number in this species equals 3 as in other species of the genus Anopheles [10]. The polytene chromosome complement consists of 5 chromosome arms: 4 autosomal arms and one X chromosome arm (Fig. 1). Autosomal arms usually are separated from each other on a preparation because of fragile connections between the pericentromeric regions. The $\mathrm{X}$ chromosome is the shortest, and the $3 \mathrm{R}$ arm is the longest. The arm proportions (Table 2) are similar to those of chromosomes in salivary gland cells of other species of the Maculipennis group [25]. Interestingly, the banding patterns of ovarian nurse cell polytene chromosomes in $A n$. beklemishevi are better quality than the banding patterns in other species in the Maculipennis group. The chromosomes have sharp band-interband borders and distinguishable thin bands. This feature differentiates $A n$. beklemishevi from other Palearctic members of the Maculipennis group, such as An. atroparvus [25].

The chromosome map of An. beklemishevi is divided into 39 numbered divisions and 122 lettered subdivisions (Fig. 2). Although division borders and nomenclature were adopted from the previously developed salivary gland chromosome map of An. beklemishevi [8], we

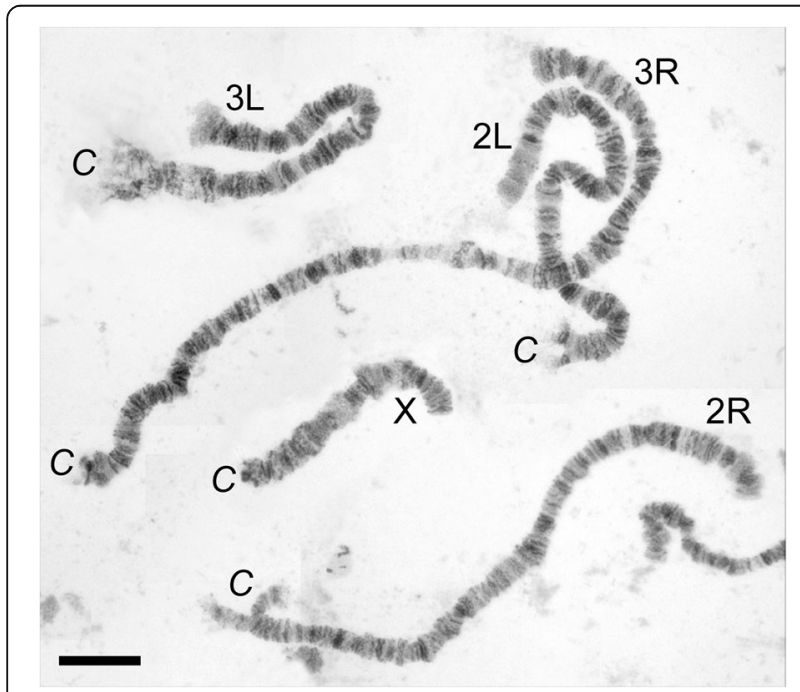

Fig. 1 The chromosome complement in ovarian nurse cells of $A n$. beklemishevi. Chromosome arms are shown as $\mathrm{X}, 2 \mathrm{R}, 2 \mathrm{~L}, 3 \mathrm{R}$ and $3 \mathrm{~L}$. Pericentromeric regions are labeled as C. Scale-bar: $20 \mu \mathrm{m}$
Table 2 Measurements of polytene chromosomes from An. beklemishevi ovarian nurse cells

\begin{tabular}{llll}
\hline & X & 2 & 3 \\
\hline Average length $(\mu \mathrm{m})$ & 133 & 711 & 759 \\
Relative length (\%) & 8.4 & 44.3 & 47.4 \\
Centromere position (\%) & na & 48.8 & 38.0 \\
\hline
\end{tabular}

reversed the order of lettered subdivisions in arms $2 \mathrm{~L}$ and $3 \mathrm{~L}$ to follow the order of numbered divisions.

Chromosomes in An. beklemishevi have welldistinguishable landmarks that simplify their identification. The sex chromosome $\mathrm{X}$, the shortest chromosome, has a round pericentric heterochromatin band, usually followed by a neighboring thin band. In the middle of the chromosome, in region $2 \mathrm{BC}$, there is a set of bands surrounded by light diffuse regions. The telomere region has a set of multiple thin bands.

Chromosome 2 is intermediate in length. The $2 \mathrm{R}$ arm has an asynaptic pericentromeric region without any remarkable bands. The telomere end is slightly flared and contains dark bands in region 6A-C. Two sets of dark bands in the middle of the arm in regions $9 \mathrm{~A}$ and $9 \mathrm{~B}$ are remarkable landmarks for the $2 \mathrm{R}$ arm. The $2 \mathrm{~L}$ arm is similar to the $2 R$ arm in length but could be distinguished from the $2 R$ arm by the pericentromeric end, which is slightly asynaptic. The area of asynapsis in $2 \mathrm{~L}$ is shorter than that in $2 \mathrm{R}$ and is restricted by a dark band in region $15 \mathrm{~A}$. The telomere end of the $2 \mathrm{~L}$ arm has almost no bands in regions 20D-21A and looks significantly lighter compared with the dark-banded telomere of $2 \mathrm{R}$ arm.

Chromosome 3 is the longest in the chromosomal complement. The $3 \mathrm{R}$ arm has no asynapsis in the pericentric region, which is usually terminated by a short dark band with flare fibers in region $32 \mathrm{C}$. The telomeric end of $3 \mathrm{R}$ is notably flared and marked by a wide light interband surrounded by two thin, dark bands in region 22B. Three bands in regions $28 \mathrm{~A}, 28 \mathrm{C}$, and in $29 \mathrm{~A}$ can serve as additional landmarks for $3 \mathrm{R}$. The $3 \mathrm{~L}$ arm is the shortest autosomal arm. A long asynaptic region is located at the centromeric end of $3 \mathrm{~L}$. The telomeric end has no clear bands in region 39ED. The main landmark for $3 \mathrm{~L}$ is a so-called "bird eye" landmark in region 36C. It is a dark, dot-shaped band, similar to a pupil, surrounded by a dark, long band, similar to an eyebrow.

\section{Physical mapping of orthologous genes to An. beklemishevi polytene chromosomes}

To test the utility of the An. beklemishevi highresolution chromosome map for physical gene mapping, we hybridized four orthologous genes of An. atroparvus to $\mathrm{X}, 2 \mathrm{R}, 3 \mathrm{R}$, and $3 \mathrm{~L}$ arms. Four PCR probes were designed to amplify the unique sequences from gene exons (Table 3). All probes produced clear and unique signals 

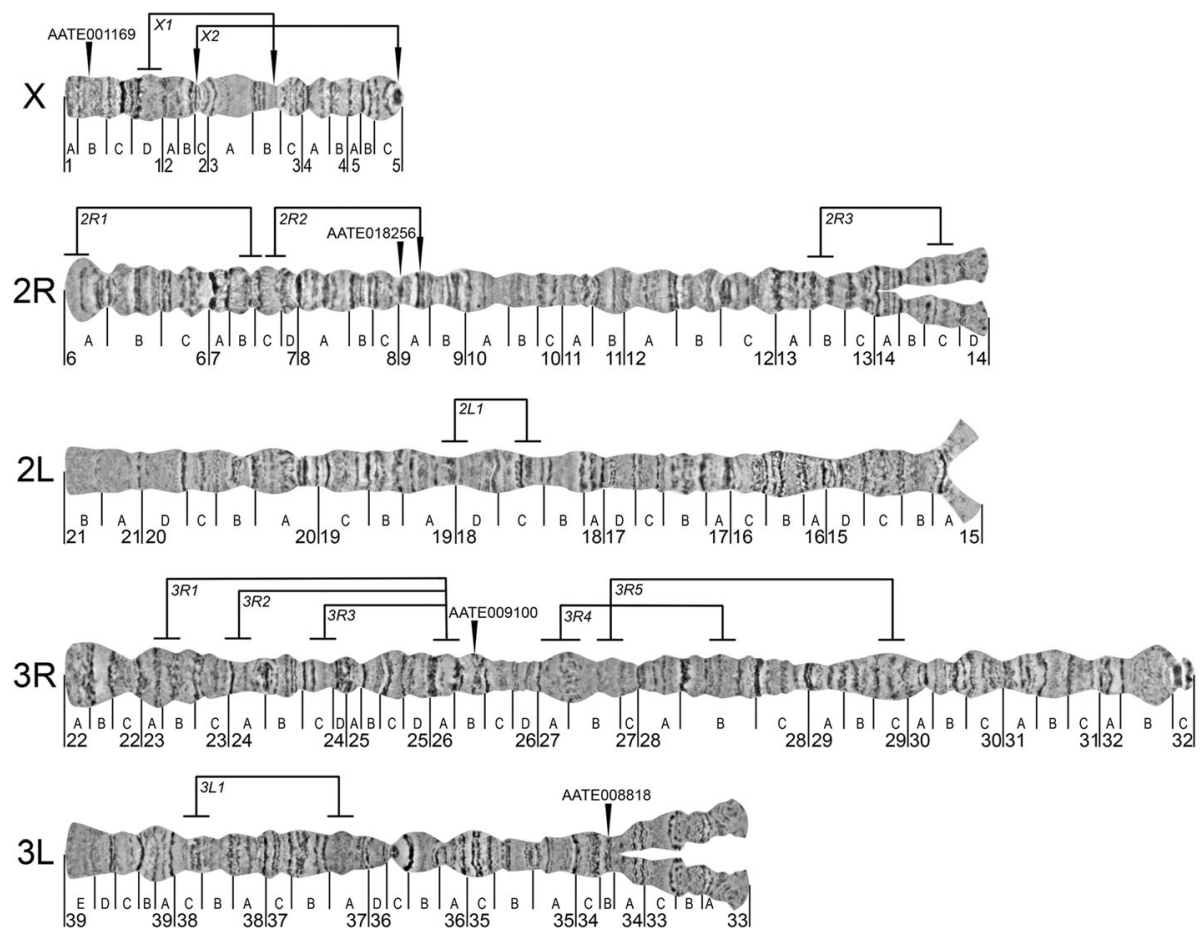

Fig. 2 A standard cytogenetic photomap of ovarian nurse cell chromosomes of Anopheles beklemishevi. Chromosome arms are shown as X, 2R, $2 \mathrm{~L}, 3 \mathrm{R}$, and $3 \mathrm{~L}$. The vertical lines below the chromosomes indicate the boundaries of numbered and lettered divisions and subdivisions, respectively. Vertical arrowheads above the chromosomes indicate the locations of DNA probes of the four An. atroparvus genes orthologues. Brackets show inversions. Brackets with arrows indicate the exact positions of the inversions on $\mathrm{X}$ chromosome

(Fig. 3) and were successfully mapped to the chromosome map based on the banding patterns (Fig. 2).

To identify the exact cytogenetic positions of the proximal breakpoint of the X1 inversion, we mapped two DNA probes chosen from 24 genes mapped to An. atroparvus chromosomes [9]. The selected probes were expected to flank the proximal breakpoint of $\mathrm{X} 1$ inversion based on similarity of the banding pattern between the two species. Random primer-labelled DNA probes of genes AATE017741 and AATE010870 were hybridized to An. beklemishevi heterozygous chromosomes X01 that formed heterozygous loops (Fig. 4a). DNA probe AATE010870 was found in region $3 \mathrm{C}$ band 2 in both homologues, whereas juxtaposed gene AATE017741 was located in region 3B band 3 of one homologous chromosome and was found in region $1 \mathrm{D}$ of another homologue (Fig. $4 \mathrm{~b}$ ) indicating that the proximal breakpoint of this inversion is located between these two DNA probes.

To map the distal and proximal breakpoints of inversion $\mathrm{X} 2$, we micro-dissected the whole $2 \mathrm{BC}$ region of the $\mathrm{X}$ chromosome with the standard X00 arrangement. According to our cytogenetic analysis, this region crosses the distal breakpoint of X2 inversion. On heterozygous chromosome X02 (Fig. 4c), FISH of a microdissected DNA probe showed three signals (Fig. 4d). The longest signal marked entire region $2 \mathrm{BC}$ on the standard homologue. Another homologue had 2BC divided by the inversion into two fragments revealed by the probe as two signals. One of them was in region $2 \mathrm{BC}$ as standard, whereas the other was transposed to the pericentromeric

Table 3 The list of primer sequences for An. atroparvus genes used as PCR-based DNA markers to hybridize with chromosomes of An. beklemishevi

\begin{tabular}{llll}
\hline An. atroparvus gene & Chromosome & Forward primer & Reverse primer \\
\hline AATE001169 & $X$ & TGGAGGACGTTCGGTTTCTG & AATTCCGACTGCTCGCTAGG \\
AATE017741 & $x$ & GCAGCTGTTATGTGCTTCGG & GTAGTACACCCAGTAGCGCC \\
AATE010870 & $X$ & CCAAATCTTCTCAATCGCCCG & CGTCAAGTCGTCCTCGGAAT \\
AATE018256 & $2 \mathrm{R}$ & AGTGTGTACTGCATGGCGA & ACGATGGTCGCATAGAGCAG \\
AATE009100 & BR & GGTGTGGTGCTGAAAATGTG & CACCTACACCCAGAGGCATT \\
AATE008818 & SL & TCATGCTCGGCTGGTCATT & CGTGAATGTGGTACGCAACG \\
\hline
\end{tabular}



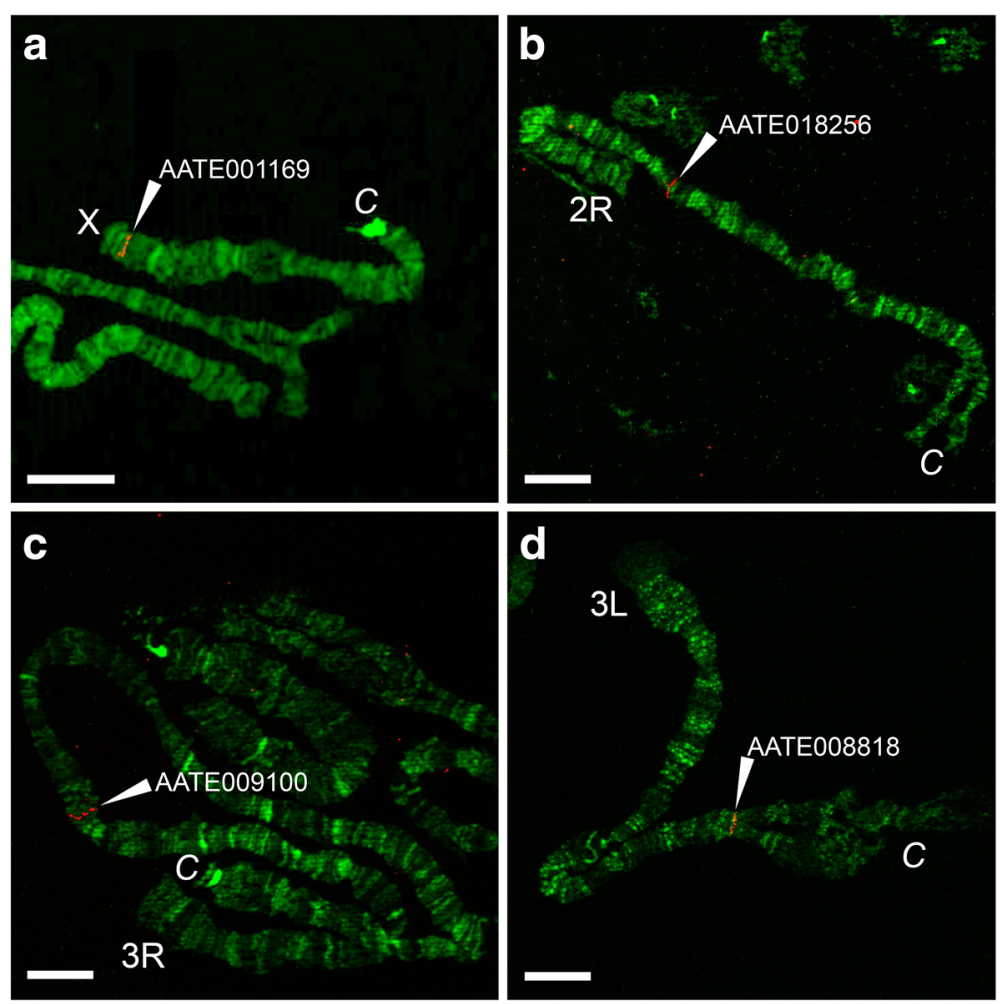

Fig. 3 FISH on chromosomes of An. beklemishevi. The red signals (indicated by arrowheads) demonstrate the position of the orthologous An. artropanus genes: AATE001169 (a), AATE018256 (b), AATE009100 (c) and AATE008818 (d) on An. beklemishevi chromosomes X, 2R, 3R and 3L, respectively. Scale-bars: $20 \mu \mathrm{m}$

region adjacent to region $5 \mathrm{C}$ band 3 where the other inversion breakpoint resides. Therefore, a single DNA probe FISH allowed us to map both breakpoints of the $\mathrm{X} 2$ inversion.

\section{Inversions in natural populations of An. beklemishevi} We analyzed inversion polymorphism in 18 collections from 13 Eurasian populations of An. beklemishevi. For two populations in Western Siberia, Kolarovo and Teguldet, collections were taken repeatedly during 3 and 4 years, respectively. For the inversion polymorphism analysis, we used both the original cytogenetic map for polytene chromosomes from salivary glands of larvae [8] and our newly developed map for the adult stage of mosquitoes. A total of 371 mosquitoes were analyzed at larva and adult stages. For the first time, 110 adult

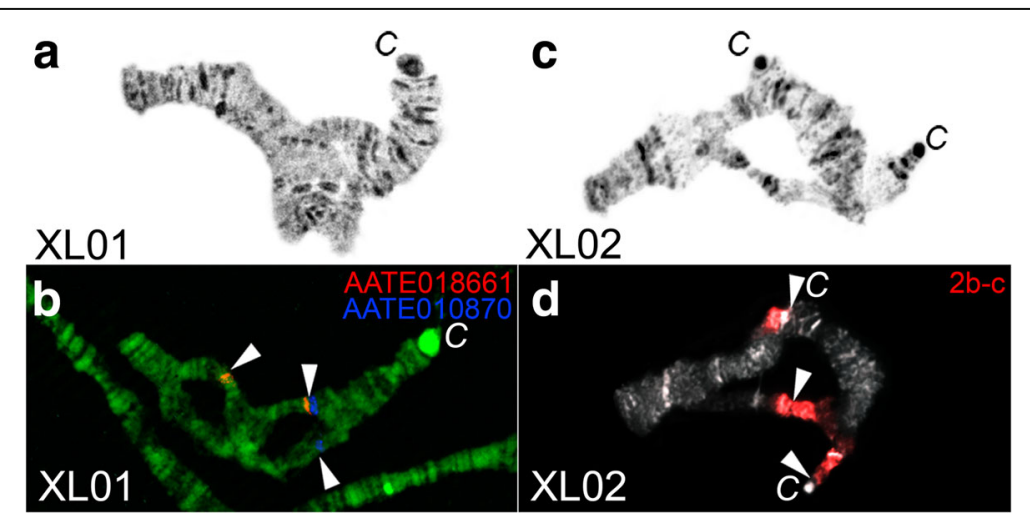

Fig. 4 Physical mapping of the proximal breakpoint of $X 1(\mathbf{a}, \mathbf{b})$ and breakpoints of $X 2(\mathbf{c}, \mathbf{d})$ polymorphic inversions in An. beklemishevi. Phase contrast images of heterozygous $X$ are shown on panels $\mathbf{a}$, $\mathbf{c}$, respectively. FISH of gene-specific DNA probes and micro-dissected DNA probes are demonstrated on panels $\mathbf{b}$, $\mathbf{d}$, respectively 
females were included in the inversion polymorphism analysis. Our data confirmed previous observations that An. beklemishevi is a polymorphic species [8]. Data on the inversion polymorphism are summarized in Table 1. In total, 4 of 12 well-known polymorphic inversions were found in 13 locations: X1, X2, 3R1 and 3R3. Inversion X1 was recorded in two distant locations of Karelia (Belomorsk) and Western Siberia (Chainsk). Inversion $\mathrm{X} 2$ is widespread from the White Sea to Siberia. Inversions 3R1 and 3R3 were detected only in a single population in Belomorsk.

All inversions, without exception, were found as heterozygotes only. Based on statistical analysis (Additional file 1: Table S1), none of the inversions displayed a significant $(P$ $<0.05)$ departure from the Hardy-Weinberg equilibrium, suggesting that the absence of inverted arrangements of the chromosomal inversions is a result of the low frequency of inversions in the populations. However, a lethal effect of the inversion in a homozygote is possible and requires further experimental investigations.

\section{Discussion}

We developed a high-resolution standard cytogenetic photomap for An. beklemishevi, which is one of the most northern species of the Maculipennis group and genus Anopheles. This map was developed using high-quality digital images similar to cytogenetic photomaps of other mosquito species [25, 29-34]. The goal of this work was to create a cytogenetic map that would be applicable for genome mapping and population genetics. In our study, the An. beklemisevi map was validated by mapping FISH signals of 4 PCR-amplified probes on $\mathrm{X}, 2 \mathrm{R}, 3 \mathrm{R}$, and $3 \mathrm{~L}$ chromosome arms. In addition, we mapped breakpoints on the X chromosome of An. beklemishevi using microdissected DNA probes. We demonstrated that the new cytogenetic map can serve as an effective tool for physical genome mapping of An. beklemishevi. Our study also confirmed the utility of the newly developed chromosome map for population genetic studies using adult females because this map was developed based on ovarian nurse chromosomes from the female mosquito. All population genetic studies conducted in the past included only the larval stage of mosquitoes because the map previously developed for An. beklemishevi was for the salivary gland chromosomes of fourth-instar larvae [8]. To our knowledge, inversion polymorphism in the adult stage of $A n$. beklemishevi was studied for the first time here.

The analysis of inversion polymorphism in natural populations of An. beklemishevi demonstrated that chromosomal variations in this species are related to the geographical distribution of An. beklemishevi. This species inhabits the northern areas in the taiga zone. According to our data, the southern boundary of the species range is fragmented and located in the subzone of the southern taiga (the belt of mixed and broadleaved forests). The northern boundary passes along the border of the taiga zone and forest tundra, near the 65th parallel in Europe and the 67th parallel in Asia [3, 35]. A high level of inversion polymorphism was noted in the subzone of the northern taiga: Belomorsk (Table 3), Syktyvkar and Berezovo [8]. Many inversions have also been identified in the adjacent area of the middle taiga: Petrozavodsk and Novaya Burka in the Tomsk region [8]. We propose that the central part of the taiga, which was formed since the end of the Neogene, provides optimal conditions for An. beklemishevi [36]. It should be expected that inversions of autosomes 2 and 3 will occur mainly in northern populations, where the species range does not overlap with the sibling species An. messeae. With the rising of global temperature, the An. messeae may displace An. beklemishevi in the subzone of the southern taiga. For example, a process of elimination of An. beklemishevi from the population has been demonstrated in Tomsk (South of Western Siberia). The proportion of this species in July samples has been reduced significantly from 0.109 in 1989 to 0.030 in 1998 [37]. The same process has been observed in two other locations in Western Siberia: Kolarovo and Cherga [3]. Reduction in the number of mosquitoes can lead to loss of chromosomal polymorphism in southern populations of An. beklemishevi. The effect of global warming has been shown for the population of another Palearctic member from the Maculipennis group, An. maculipennis [38].

In contrast to the autosomal rearrangements, inversions of chromosome $\mathrm{X}$ have a particular importance in the establishment of chromosomal polymorphism, especially the $\mathrm{X} 2$ inversion that is common throughout the species range (Table 3). Here we found no difference from the Hardy-Weinberg equilibrium for both autosomal and $\mathrm{X}$ chromosomal inversions. Nevertheless, overdominance of X2 was described in larvae from Shchuchye Lake which neighbors Teletskoe Lake (Gorniy Altay, Russia) [35]. Obviously, overdominance is the main way to maintain the X2 polymorphism; no homozygous X2 was detected, but heterozygotes dominated this population. Unlike X2, two homozygotes of X1 were identified in Syktyvkar [8]. The presence of common inversions may reflect the unity of the species population system throughout the range of An. beklemishevi.

\section{Conclusions}

In this study, we developed a high-quality cytogenetic map for An. beklemishevi, a member of the Maculipennis group of malaria mosquitoes. Our study has demonstrated that a chromosomal photomap for $A n$. beklemishevi can be utilized for physical genome mapping. We mapped to the chromosomes four random 
genes and the boundaries of two chromosomal inversions in chromosome $\mathrm{X}$ and indicated the positions of 12 other polymorphic inversions on the map. Polymorphic inversions were found in all parts of the species range. The highest level of chromosomal variations was noted North of the taiga zone. The analysis of the inversion polymorphism in natural populations of An. beklemishevi provides important insight into adaptive genetic variations of this species.

\section{Additional file}

Additional file 1: Table S1. Chromosomal polymorphisms in populations of Anopheles beklemishevi. (DOCX $102 \mathrm{~kb}$ )

\section{Acknowledgements}

We thank Melissa Wade for editing the text.

\section{Funding}

Russian Science Foundation grant 15-14-20011 to IVS.

\section{Availability of data and materials}

All the data presented here are available in the text, figures and tables of this article. The material is available upon request.

\section{Authors' contributions}

GNA carried out most of the cytogenetic studies and drafted the manuscript- MIG performed the population analysis and drafted the manuscript- AAK analyzed the FISH data- AVM participated in the population analysis. AIV prepared chromosomal preparations and performed FISH. VNS provided laboratory space, resources and discussed the data. IVS participated in the design of the study and writing the manuscript. MVS designed and coordinated the study and wrote most of the manuscript. All authors read and approved the final manuscript.

Ethics approval and consent to participate Not applicable.

\section{Consent for publication}

Not applicable.

\section{Competing interests}

The authors declare that they have no competing interests.

\section{Publisher's Note}

Springer Nature remains neutral with regard to jurisdictional claims in published maps and institutional affiliations.

\footnotetext{
Author details

${ }^{1}$ Laboratory of Ecology, Genetics and Environmental Protection, Tomsk State University, Tomsk, Russia. ${ }^{2}$ Department of General Biology and Ecology, Moscow Regional State University, Moscow, Russia. ${ }^{3}$ Virginia Tech, Department of Entomology, Fralin Life Science Institute, Blacksburg, VA, USA.
}

Received: 19 September 2017 Accepted: 17 January 2018 Published online: 27 March 2018

\section{References}

1. Stegnii VN, Kabanova VM. Cytoecological study of natural populations of malaria mosquitoes on the USSR territory. 1. Isolation of a new species of Anopheles in Maculipennis complex by the cytodiagnostic method. Med Parazitol (Mosk). 1976:45(2):192-8

2. Harbach RE. The classification of genus Anopheles (Diptera: Culicidae): a working hypothesis of phylogenetic relationships. Bull Entomol Res. 2004; 94(6):537-53.
3. Novikov YM. On the ecology and range of Anopheles beklemishevi (Diptera: Culicidae) with reference to the taxonomy of An. lewisi. J Vector Ecol. 2016; 41(2):204-14.

4. Hay SI, Sinka ME, Okara RM, Kabaria CW, Mbithi PM, Tago CC, et al. Developing global maps of the dominant Anopheles vectors of human malaria. PLoS Med. 2010;7(2):e1000209.

5. Sinka ME, Bangs MJ, Manguin S, Coetzee M, Mbogo CM, Hemingway J, et al. The dominant Anopheles vectors of human malaria in Africa, Europe and the Middle East: occurrence data, distribution maps and bionomic precis. Parasit Vectors. 2010;3:117.

6. Sokolova MI, Snow KR. Malaria vectors in European Russia. Eur Mosq Bull. 2002;12:1-6.

7. Novikov YM. Rearing of Anopheles beklemishevi (Diptera: Culicidae) and the possibility of its hybridization with An. atroparvus under laboratory conditions. J Vector Ecol. 2016:41(2):320-2.

8. Stegniy VN, Novikov lu M, Kabanova VM. Cytogenetic analysis and distribution of Anopheles beklemishevi. Zool J. 1978;57(6):873-6.

9. Neafsey DE, Waterhouse RM, Abai MR, Aganezov SS, Alekseyev MA, Allen JE, et al. Mosquito genomics. Highly evolvable malaria vectors: the genomes of 16 Anopheles mosquitoes. Science. 2015;347(6217):1258522.

10. Rai KS. A comparative study of mosquito karyotypes. Ann Ent Soc Amer. 1963:56:160-70.

11. Kitzmiller JB, Frizzi G, Baker R. Evolution and speciation within the Maculipennis complex of the genus Anopheles. In: Wright JW, editor. Genetics of insect vectors of disease. Amsterdam-London-New York: Elsevier Publishing Company; 1967. p. 151-210.

12. Stegnii VN, Kabanova VM, Novikov YM, Pleshkova GN. Inversion polymorphism in malaria mosquito Anopheles messeae. I. Distribution of the inversions in the species areal. Genetika. 1976;12(4):47-55.

13. Pleshkova GN, Stegnii VN, Novikov lu M, Kabanova VM. Inversion polymorphism in the malarial mosquito, Anopheles messeae. III. The temporal dynamics of the inversion frequencies in the population of the center of a geographic range. Genetika. 1978;14(12):2169-76.

14. Stegnii VN. Inversion polymorphism of the malarial mosquito Anopheles messeae. IV. The stability of the frequency distribution of the inversions by species area. Genetika. 1983;19(3):466-73.

15. Stegnii VN. Inversion polymorphism of the malarial mosquito Anopheles messeae. $V$. The interaction of different chromosomal inversions in the spatial area. Genetika. 1983;19(3):474-82.

16. Stegnii VN, Kabanova VM. Inversion polymorphism in the malaria mosquito Anopheles messeae. VI. Local selection and 3-dimensional differentiation of the inversion gene complexes for fertility. Genetika. 1985;21(12):1970-3.

17. Gordeev MI, Stegnii VN. Inversion polymorphism in the malaria mosquito Anopheles messeae. VII. Fertility and the population genetics structure of the species. Genetika. 1987;23(12):2169-74.

18. Gordeev MI, Stegnii VN. Inversion polymorphism of the malaria mosquito Anopheles messeae. VIII. Distribution of larvae in biotopes under conditions of co-habitation with Anopheles beklemishevi. Genetika. 1989;25(2):283-91.

19. Rusakova AM, Artemov GN, Potapova NK, Stegnii VN. Inversion polymorphism in malarial mosquito Anopheles messeae natural populations from the north-eastern region of the range. Genetika. 2010;46(10):1311-3.

20. Stegniy VN, Kabanova VM. Cytoecological study of indigenous populanions of the malaria mosquito in the territory of the USSR. 1. Identification new species of Anopheles in the maculipennis complex by the cytodiagnostic method. Mosq Systematics. 1978;10:1-12.

21. Sharakhova MV, Stegniy VN. Interspecies differences in the ovarian trophocyte precentromere heterochromatin structure and evolution of the malaria mosquito complex Anopheles maculipennis. Genetika. 1997;33(12):1640-8.

22. Kabanova VM, Kartashova NN, Stegii VN. Kariological study of malaria mosquito in the middle Ob region. Report 1. Characteristics of the Anopheles maculipennis messeae karyotype. Tsitologiya. 1972;14:630-6.

23. Artemov GN, Vasil'eva OY, Stegniy VN. Comparative analysis of DNA sequences of regions of $X$-chromosome attachment to the nuclear envelope of nurse cells Anopheles messeae fall. Genetika. 2015;51(7):821-5.

24. National Ceneter for Biotechnology Information. 2018. http://www.ncbi.nlm. nih.gov/tools/primer-blast/. Accessed 8 Jan 2018.

25. Artemov GN, Sharakhova MV, Naumenko AN, Karagodin DA, Baricheva EM, Stegniy VN, et al. A standard photomap of ovarian nurse cell chromosomes in the European malaria vector Anopheles atroparvus. Med Vet Entomol. 2015;29(3):230-7.

26. VectorBase. 2017. https://www.vectorbase.org/. Accessed 11 Dec 2017. 
27. Sharakhova MV, Xia A, Tu Z, Shouche YS, Unger MF, Sharakhov IV. A physical map for an Asian malaria mosquito, Anopheles stephensi. Am J Trop Med Hyg. 2010;83(5):1023-7.

28. Preacher, K. J . Calculation for the chi-square test: an interactive calculation tool for chi-square tests of goodness of fit and independence 2005. http:// quantpsy.org/. Accessed 25 July 2005.

29. Sharakhov IV, Sharakhova MV, Mbogo CM, Koekemoer LL, Yan G. Linear and spatial organization of polytene chromosomes of the African malaria mosquito Anopheles funestus. Genetics. 2001;159(1):211-8.

30. Sharakhova MV, Xia A, McAlister SI, Sharakhov IV. A standard cytogenetic photomap for the mosquito Anopheles stephensi (Diptera: Culicidae): application for physical mapping. J Med Entomol. 2006;43(5):861-6.

31. George P, Sharakhova MV, Sharakhov IV. High-resolution cytogenetic map for the African malaria vector Anopheles gambiae. Insect Mol Biol. 2010;19(5): 675-82.

32. Sharakhova MV, Antonio-Nkondjio C, Xia A, Ndo C, Awono-Ambene P, Simard F, et al. Cytogenetic map for Anopheles nill: application for population genetics and comparative physical mapping. Infect Genet Evol. 2011:11(4):746-54.

33. Unger MF, Sharakhova MV, Harshbarger AJ, Glass P, Collins FH. A standard cytogenetic map of Culex quinquefasciatus polytene chromosomes in application for fine-scale physical mapping. Parasit Vectors. 2015;8:307. https://doi.org/10.1186/s13071-015-0912-4.

34. Artemov GN, Peery AN, Jiang X, Tu Z, Stegniy VN, Sharakhova MV, et al. The physical genome mapping of Anopheles albimanus corrected scaffold misassemblies and identified interarm rearrangements in genus Anopheles. G3 (Bethesda). 2017;7(1):155-64.

35. Perevozkin VP, Printseva AA, Bondarchuk SS, Gordeev MI. Spatial distribution and karyotypic composition of Anopheles mosquitoes (Diptera, Culicidae) in the environs of Teletskoye Lake. Rus J of Ecol. 2012;43(3):210-7.

36. Richter GD, editor. Natural Conditions And Natural Resources of the USSR Academy of Sciences USSR Press. Moscow. 1963;1:488.

37. Gordeev MI, Ejov MN. Global warming and variation in the chromosoma composition of Siberian malaria mosquito populations. Dokladi Biol Sci. 2004;395:554-7.

38. Novikov YM, Vaulin OV. Expansion of Anopheles maculipennis s.s. (Diptera: Culicidae) to northeastern Europe and northwestern Asia: causes and consequences. Parasit Vectors. 2014;7:389.

\section{Submit your next manuscript to BioMed Central and we will help you at every step:}

- We accept pre-submission inquiries

- Our selector tool helps you to find the most relevant journal

- We provide round the clock customer support

- Convenient online submission

- Thorough peer review

- Inclusion in PubMed and all major indexing services

- Maximum visibility for your research

Submit your manuscript at www biomedcentral.com/submit

) Biomed Central 